\title{
Prevalence of Middle East Respiratory Syndrome Coronavirus in Dromedary Camels, Tunisia
}

\author{
Simone Eckstein, Rosina Ehmann, Abderraouf Gritli, Houcine Ben Yahia, Manuel Diehl, \\ Roman Wölfel, Mohamed Ben Rhaiem, Kilian Stoecker, ${ }^{1}$ Susann Handrick, ${ }^{1}$ Mohamed Ben Moussa ${ }^{1}$
}

Free-roaming camels, especially those crossing national borders, pose a high risk for spreading Middle East respiratory syndrome coronavirus (MERS-CoV). To prevent outbreaks, active surveillance is necessary. We found that a high percentage of dromedaries in Tunisia are MERS-CoV seropositive $(80.4 \%)$ or actively infected (19.8\%), indicating extensive MERS-CoV circulation in Northern Africa.

$\mathrm{M}$ iddle East respiratory syndrome (MERS) coronavirus (MERS-CoV) has the highest lethality of all know human coronaviruses; the case-fatality rate is $34.3 \%$ (1). The virus, first isolated in Saudi Arabia in 2012 (2), most likely originates from bats (3). However, several studies suggest that the zoonosis is mainly transmitted to humans by dromedary camels (Camelus dromedarius) (4-6).

As of January 2020, a total of 2,519 human MERS$\mathrm{CoV}$ infections and 866 related deaths had been reported to the World Health Organization from 27 countries. Most of these cases (84.2\%), including 788 related deaths, occurred in Saudi Arabia (1).

Given the close trading links between the Middle East and Africa, the risk for transferring the zoonosis is high. Tunisia is not a popular trading location, which makes undocumented transfers of dromedary camels within the country or with neighboring countries difficult to track. Only 3 human MERS cases have been imported from Qatar (7), and no autochthonous MERS-CoV infections have been reported for Tunisia. However, severe underestimation of human

Author affiliations: Bundeswehr Institute of Microbiology, Munich, Germany (S. Eckstein, R. Ehmann, M. Diehl, R. Wölfel,

K. Stoecker, S. Handrick), Ministry of National Defense, General Directorate of Military Health, Veterinary Service, Tunis, Tunisia (A. Gritli, H. Ben Yahia, M. Ben Rhaiem), Military Hospital of Instruction of Tunis Department of Virology, Tunis (M. Ben Moussa)

DOI: https://doi.org/10.3201/eid2707.204873
MERS cases is highly probable because of the broad range of manifestations, from asymptomatic infection to acute pneumonia.

Furthermore, epidemiologic surveillance of MERS-CoV is limited in Tunisia, and no respective data for neighboring countries is publicly available. Two studies analyzing MERS-CoV prevalence in dromedaries in Tunisia reported high seropositivity of the sampled animals $(49.0 \%$ and $87.3 \%)(8,9)$. However, those studies analyzed dromedary camels from livestock markets, slaughterhouses, and meat farms, without representing natural habitats. This limitation complicates drawing realistic conclusions about geographic and age-dependent distributions. We investigated the prevalence of MERS-CoV in dromedary camels in Tunisia primarily by sampling animals that roam freely through the desert during summer to determine an authentic representation of the distribution pattern.

\section{The Study}

Winter is mating and birthing season for dromedary camels. Therefore, animals kept for milk and meat production gather in areas that provide access to salty plants and other minerals. This environment provides an optimal opportunity to catch and examine large numbers of animals from different herds and origins, given that the camels that roam freely through the desert the rest of the year congregate simultaneously.

In January 2020, we collected serum samples and nasal swabs of 382 gathered animals in Tunisia. We sampled an additional 119 camels used for transport or patrol purposes, all of which were males and kept enclosed. The specimens were collected from 20 different locations within the Kebili Governorate (Table; Figure 1, panel A). Furthermore, serum samples of 22 camel keepers and 2 veterinarians were obtained. We 
have compiled details of our sampling and testing methods (Appendix, https://wwwnc.cdc.gov/EID/ article/27/720-4873-App1.pdf).

We analyzed all 501 dromedary serum samples for MERS-CoV-specific antibodies by ELISA and found $80.4 \%$ to be seropositive for MERS-CoV IgG. At $85.7 \%$, MERS-CoV seropositivity was higher in female than in male camels (65.6\%) (Table; Figure 1, panel A).

Although none of the calves (0-6 months of age) and $4.9 \%$ of the juvenile camels (6-24 months of age) were seropositive for antibodies against MERS-CoV, relative seropositivity increased with age (Table). None of the camel keepers or veterinarians was seropositive, indicating no previous MERS-CoV infection.

Screening the dromedary nasal swab specimens for active virus infections with real-time reverse tran- scription PCR revealed MERS-CoV RNA in 19.8\%. However, cycle thresholds $>30$ (for all but 6 samples) indicated low virus concentrations. Female animals (23.0\%) actively shed MERS-CoV RNA, whereas only $10.7 \%$ of the male camel specimens were PCRpositive. In contrast to the immunologic findings, a high percentage $(40 \%)$ of juvenile camels ( $<2$ years of age) shed MERS-CoV RNA, compared with $17.8 \%$ of the adult camels that tested positive (Table, Figure 1, panel A)

In summary, 433 of 501 dromedaries tested positive for MERS-CoV. A total of 334 animals were seropositive for MERS-CoV IgG but did not shed MERSCoV RNA. Of these, 30 dromedary swab specimens contained MERS-CoV RNA, but no specific antibodies were found in the respective serum samples. Sixty-nine PCR-positive dromedary camels also had

\begin{tabular}{|c|c|c|c|}
\hline Sampling parameter & No. dromedaries & $\begin{array}{l}\text { ELISA serologic testing, no. (\%) } \\
\text { positive for MERS-CoV IgG }\end{array}$ & $\begin{array}{l}\text { Molecular biology rRT-PCR, no. } \\
\text { (\%) positive for MERS-CoV RNA }\end{array}$ \\
\hline \multicolumn{4}{|l|}{ Sex } \\
\hline $\mathrm{M}$ & 131 & $86(65.6)$ & $14(10.7)$ \\
\hline $\mathrm{F}$ & 370 & $317(85.7)$ & $85(23.0)$ \\
\hline$p$ value & & $<0.05$ & $<0.01$ \\
\hline \multicolumn{4}{|l|}{ Age group } \\
\hline Juvenile & 45 & $2(4.4)$ & $18(40.0)$ \\
\hline $0-6 \mathrm{mo}$ & 4 & $0(0)$ & $1(25.0)$ \\
\hline $6-24 \mathrm{mo}$ & 41 & $2(4.9)$ & $17(41.5)$ \\
\hline Adult & 456 & $401(87.9)$ & $81(17.8)$ \\
\hline $2-6 y$ & 81 & $62(76.5)$ & $19(23.5)$ \\
\hline $6-12 y$ & 179 & $157(87.7)$ & $28(15.6)$ \\
\hline $12-25 y$ & 190 & $176(87.9)$ & $32(16.8)$ \\
\hline$>25 y$ & 6 & $6(100)$ & $2(33.3)$ \\
\hline $\mathrm{p}$ value, juvenile compared with adult & & $<0.00001$ & $<0.01$ \\
\hline \multicolumn{4}{|l|}{ Sampling site } \\
\hline Ksar Ghilane, $n=6$ & 211 & $154(73.0)$ & $49(23.2)$ \\
\hline Site 1 & 28 & $20(71.4)$ & $7(25.0)$ \\
\hline Site 2 & 20 & $8(40.0)$ & $0(0)$ \\
\hline Site 3 & 30 & $26(86.7)$ & $6(20.0)$ \\
\hline Site 4 & 20 & $19(95.0)$ & $1(5.0)$ \\
\hline Site 5 & 73 & $50(68.5)$ & $25(34.2)$ \\
\hline Site 6 & 40 & 31 (77.5) & $10(25.0)$ \\
\hline Bazma, $n=7$ & 168 & $152(90.5)$ & 32 (19.1) \\
\hline Site 1 & 25 & $24(96.0)$ & $2(8.0)$ \\
\hline Site 2 & 30 & $25(83.3)$ & $8(26.7)$ \\
\hline Site 3 & 15 & $13(86.7)$ & $3(20.0)$ \\
\hline Site 4 & 15 & $14(93.3)$ & $1(6.7)$ \\
\hline Site 5 & 21 & $20(95.2)$ & $4(19.0)$ \\
\hline Site 6 & 16 & $13(81.3)$ & $6(37.5)$ \\
\hline Site 7 & 46 & 43 (93.5) & $8(17.4)$ \\
\hline Douz, $n=5$ & 53 & $32(60.4)$ & $4(7.5)$ \\
\hline Site $1 a$ & 4 & $3(75.0)$ & $0(0)$ \\
\hline Site $1 b$ & 4 & $0(0)$ & $0(0)$ \\
\hline Site 2 & 24 & $18(75.0)$ & $3(12.5)$ \\
\hline Site 3 & 18 & $10(55.6)$ & $1(5.6)$ \\
\hline Site 4 & 3 & $1(33.3)$ & $0(0)$ \\
\hline Mahrouga, $n=2$ & 69 & $65(94.2)$ & $14(20.3)$ \\
\hline Site 1 & 42 & 40 (95.2) & $3(7.1)$ \\
\hline Site 2 & 27 & $25(92.6)$ & $11(40.7)$ \\
\hline \multicolumn{2}{|c|}{$\mathrm{p}$ value for comparisons among all 4 main sites } & 0.05 & Not significant \\
\hline Total & 501 & $403(80.4)$ & $99(19.8)$ \\
\hline
\end{tabular}

*MERS-CoV, Middle East respiratory syndrome coronavirus; rRT-PCR, real-time reverse transcription PCR. 

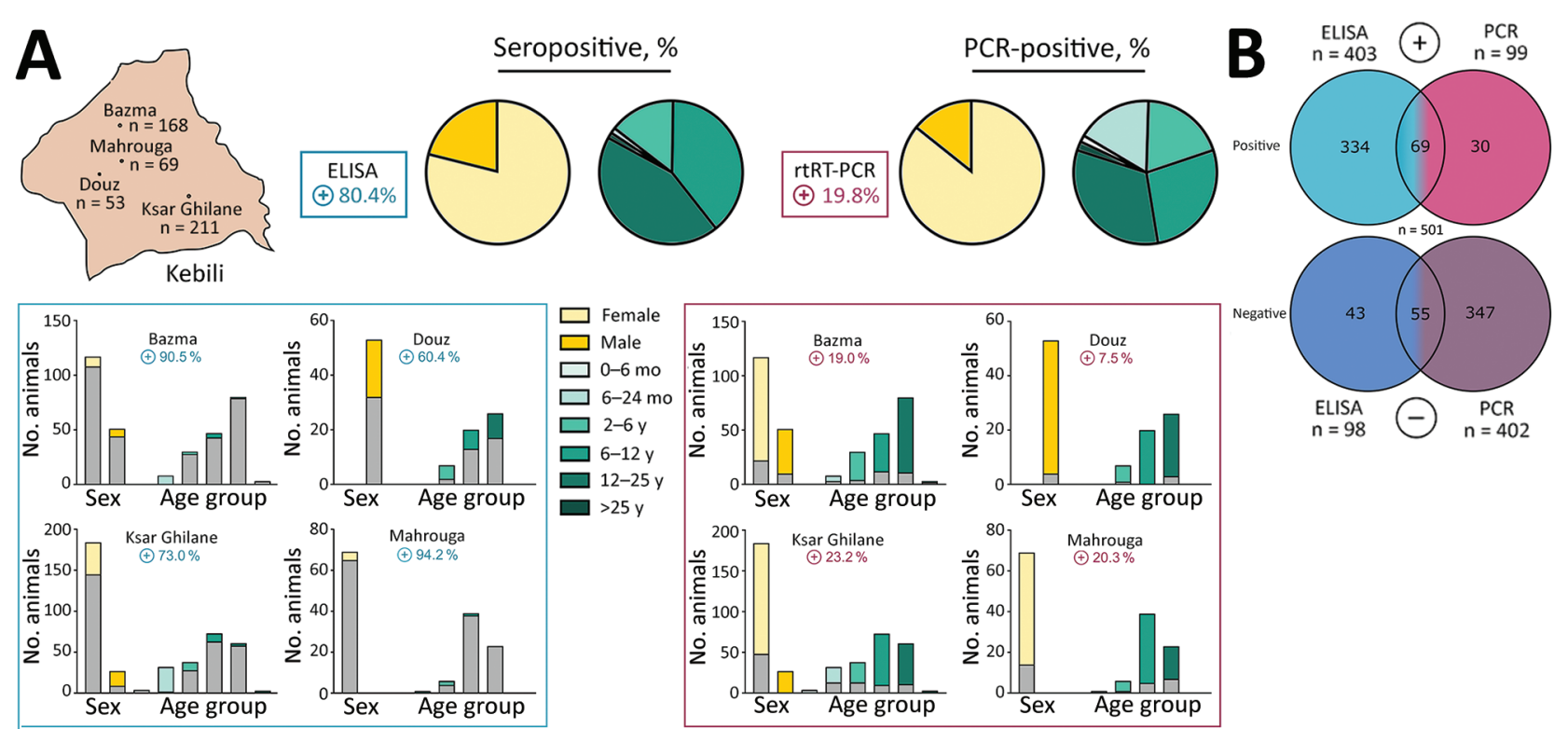

Figure 1. MERS-CoV prevalence in dromedary camels, Tunisia. A) Overview of seropositive and PCR-positive dromedaries from 4 different sampling areas (Appendix, https://wwwnc.cdc.gov/EID/article/27/720-4873-App1.pdf), by sex and age group. Blues boxes represent seropositive dromedaries and purple boxes PCR-positive dromedaries. Bars in chart represent total number of sampled animals; gray-shaded bar sections represent total number of MERS-CoV-positive animals. In the Douz area, all dromedary camels sampled were used for patrol or transport purposes and were exclusively adult male animals. B) Distribution of ELISA (blue) and PCR (purple) results, by number. Bright colors represent positive results, dark colors negative results; 2-colored areas represent animals that are either positive for both ELISA and PCR or negative for both. MERS-CoV, Middle East respiratory syndrome coronavirus;

MERS-CoV antibodies, indicating reinfection (Figure 1, panel B).

Attempts to cultivate the virus from all respective PCR-positive swab specimens were unsuccessful, most likely because of the low virus concentrations in the samples. Presumably, whole-genome sequencing did not work for the same reasons. However, we performed Sanger sequencing of cDNAs obtained from PCR-positive samples with the highest viral concentrations and subsequently conducted phylogenetic analysis with a 720-bp fragment of the spike receptorbinding protein. The analyzed nucleotide sequences from the dromedaries in Tunisia differ from previously published MERS-CoV sequences and therefore form a separate group distinct from strains found in Arabia. Two MERS-CoV isolates in Egypt, however, cluster in the same clade (Figure 2).

\section{Conclusions}

On the continent of Africa, active surveillance, longitudinal studies, and epidemiologic monitoring are scarce, and little is known about the prevalence and circulation of MERS-CoV in many regions. Whether MERS-CoV lineages in Africa have a lower tendency to cross the species barrier and infect humans is not fully understood. Therefore, closing the gaps in surveillance and virus prevalence data remains a focus for all regions with dromedary camel populations.

Seroprevalence studies in Egypt, Ethiopia, Nigeria, and Kenya all indicate MERS-CoV circulation within camel herds, reporting seropositivity rates ranging from $30 \%$ to $100 \%$ (10). For dromedaries in Tunisia, only 2 studies have been published, reporting $49 \%$ and $87.3 \%$ MERS-CoV seropositive animals and only $0.7 \%$ active viral shed $(8,9)$.

However, most studies focus on locations where large numbers of camels congregate (e.g., abattoirs, large-scale farms, harbors, or livestock markets). At these locations, dromedaries are kept at a substantially increased population density compared with their normal habitats. This practice, referred to as crowding, increases stress for individual animals (11). Under these circumstances, increased intensive animal contact can lead to higher transmission rates of various microorganisms. Crowding, in combination with animal transport, is known to promote infections of the upper and lower respiratory tract, especially in cattle (12). In contrast, the camels investigated in our study represent a rare example of MERS-CoV prevalence in animal groups with a natural herd structure in northern Africa. 
We found extensive MERS-CoV IgG seropositivity $(80.4 \%)$ and high ratios of MERS-CoV RNA (19.8\%) among dromedaries in Tunisia. Compared with adult animals, juvenile camels were more likely to have active MERS-CoV infections and less MERS-CoV IgG in their serum samples. Furthermore, some dromedaries appeared to have MERS-CoV reinfections, explained by the fact that coronaviruses tend to establish endemic infection patterns with high seroprevalence and low but continuous viral shedding in their natural host (13). Waning antibodies in combination with antigenic drift of the virus fosters reinfection events (14).

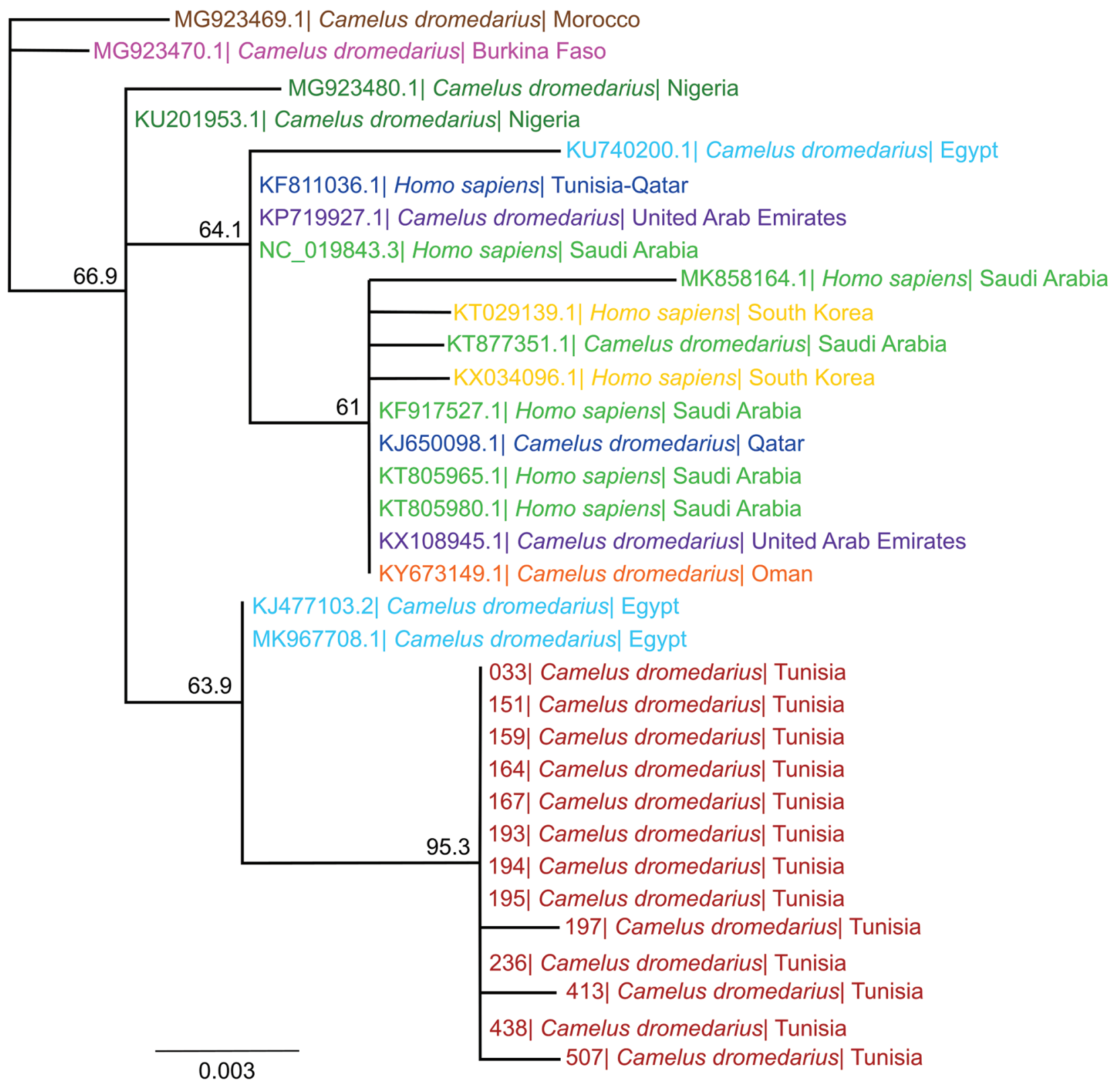

Figure 2. Phylogenetic analysis of MERS-CoV samples from dromedary camels in Tunisia, conducted by using the spike RBD. We used 720-bp fragments of the MERS-CoV spike RBD amplified from nasal swab samples of 13 dromedary camels and published RBD sequences of representative MERS-CoV strains from other countries to create the phylogenetic tree using Geneious Prime Tree Builder (Geneious Biologics, https://www.geneious.com). Branches are shaded by country: red represents sequences from Tunisia (this study); brown represents Morocco, pink Burkina Faso, dark green Nigeria, blue Egypt, dark blue Qatar, green Saudi Arabia, yellow South Korea, purple United Arab Emirates, and orange Oman. GenBank accession numbers are provided for reference sequences. Numbers indicate bootstrap values (1,000 pseudo-replicates). Scale bar indicates sequence divergence (\% nucleotide substitutions). MERS-CoV, Middle East respiratory syndrome coronavirus; RBD, receptor-binding protein. 
A limitation of our study is that the low sample size of humans tested, comprising 22 camel keepers and 2 veterinarians (data not shown), precludes drawing generalized conclusions. Furthermore, no nasal swab specimens were collected from camel keepers to check for active MERS infections. Also, no phenotypic or whole-genome analysis of MERSCoV strains from the dromedary camels was possible because virus growth and next-generation sequencing were not successful because of low viral concentrations.

In conclusion, the high seroprevalence of MERS$\mathrm{CoV}$ antibodies and the active shed of MERS-CoV RNA indicate the widespread nature of the virus in dromedaries in Tunisia. However, more extensive studies in the human and dromedary camel populations and in-depth whole-genome sequence analysis of circulating MERS-CoV strains are required to increase epidemiologic understanding of the disease and its infection dynamics.

\section{Acknowledgments}

We thank the Deutsche Gesellschaft für Internationale

Zusammenarbeit for their support by planning and organizing the study. Furthermore, we gratefully acknowledge the camel keepers in Tunisia for their participation.

This work is part of Medical Biological Defense Research Program of the Bundeswehr Medical Service and was supported by the Enable and Enhance Initiative of the federal government of Germany (Ertüchtigungsinitiative der Deutschen Bundesregierung, grant no. OR12-370.43 ERT TUN IMB).

\section{About the Author}

Dr. Eckstein is a scientist at the Bundeswehr Institute of Microbiology. Her research interests include viral and bacterial zoonoses in North Africa.

\section{References}

1. World Health Organization. MERS situation update: January 2020 [cited 2020 Dec 1]. https:/ / vlibrary.emro.who. int/idr_records/mers-situation-update-january2020

2. Zaki AM, van Boheemen S, Bestebroer TM, Osterhaus $\mathrm{AD}$, Fouchier RA. Isolation of a novel coronavirus from a man with pneumonia in Saudi Arabia. N Engl J Med. 2012;367:1814-20. https:/ / doi.org/10.1056/NEJMoa1211721

3. Anthony SJ, Gilardi K, Menachery VD, Goldstein T, Ssebide B, Mbabazi R, et al. Further evidence for bats as the evolutionary source of Middle East respiratory syndrome coronavirus. MBio. 2017;8:e00373-17. https:// doi.org/10.1128/mBio.00373-17

4. Reusken CB, Haagmans BL, Müller MA, Gutierrez C, Godeke GJ, Meyer B, et al. Middle East respiratory syndrome coronavirus neutralising serum antibodies in dromedary camels: a comparative serological study. Lancet Infect Dis. 2013;13:859-66. https://doi.org/10.1016/ S1473-3099(13)70164-6

5. Azhar EI, El-Kafrawy SA, Farraj SA, Hassan AM, Al-Saeed MS, Hashem AM, et al. Evidence for camel-tohuman transmission of MERS coronavirus. N Engl J Med. 2014;370:2499-505. https://doi.org/10.1056/NEJMoa1401505

6. Azhar EI, Hashem AM, El-Kafrawy SA, Sohrab SS, Aburizaiza AS, Farraj SA, et al. Detection of the Middle East respiratory syndrome coronavirus genome in an air sample originating from a camel barn owned by an infected patient. MBio. 2014;5:e01450-14. https://doi.org/10.1128/ mBio.01450-14

7. Abroug F, Slim A, Ouanes-Besbes L, Hadj Kacem MA, Dachraoui F, Ouanes I, et al.; World Health Organization Global Outbreak Alert and Response Network Middle East Respiratory Syndrome Coronavirus International Investigation Team. Family cluster of Middle East respiratory syndrome coronavirus infections, Tunisia, 2013. Emerg Infect Dis. 2014;20:1527-30. https:/ / doi.org/10.3201/ eid2009.140378

8. Reusken CB, Messadi L, Feyisa A, Ularamu H, Godeke GJ, Danmarwa A, et al. Geographic distribution of MERS coronavirus among dromedary camels, Africa. Emerg Infect Dis. 2014;20:1370-4. https:/ / doi.org/10.3201/eid2008.140590

9. Kandeil A, Gomaa M, Nageh A, Shehata MM, Kayed AE, Sabir JSM, et al. Middle East respiratory syndrome coronavirus (MERS-CoV) in dromedary camels in Africa and Middle East. Viruses. 2019;11:717. https:/ / doi.org/10.3390/ v11080717

10. Dighe A, Jombart T, Van Kerkhove MD, Ferguson N. A systematic review of MERS-CoV seroprevalence and RNA prevalence in dromedary camels: implications for animal vaccination. Epidemics. 2019;29:100350. https:/ / doi.org/ 10.1016/j.epidem.2019.100350

11. Proudfoot K, Habing G. Social stress as a cause of diseases in farm animals: current knowledge and future directions. Vet J. 2015;206:15-21. https://doi.org/10.1016/j.tvj1.2015.05.024

12. Yates WD. A review of infectious bovine rhinotracheitis, shipping fever pneumonia and viral-bacterial synergism in respiratory disease of cattle. Can J Comp Med. 1982;46:225-63.

13. Addie DD, Schaap IAT, Nicolson L, Jarrett O. Persistence and transmission of natural type I feline coronavirus infection. J Gen Virol. 2003;84:2735-44. https://doi.org/ 10.1099/vir.0.19129-0

14. Herrewegh AA, Mähler M, Hedrich HJ, Haagmans BL, Egberink HF, Horzinek MC, et al. Persistence and evolution of feline coronavirus in a closed cat-breeding colony. Virology. 1997;234:349-63. https:/ / doi.org/10.1006/ viro.1997.8663

Address for correspondence: Kilian Stoecker, Bundeswehr Institute of Microbiology, Neuherbergstr. 11, 80937 Munich, Germany; email: KilianStoecker@bundeswehr.org 